\title{
Grand Challenges in Conservation Science
}

\author{
Daniel T. Blumstein* \\ Department of Ecology and Evolutionary Biology, Institute of the Environment and Sustainability, University of California, Los \\ Angeles, Los Angeles, CA, United States
}

Keywords: conservation, biodiversity, human-wildlife coexistence, community-based conservation, wildlife genomics, animal conservation, plant conservation, global biodiversity

We live in an extraordinary time. Our ingenuity and access to inexpensive fossil fuels has created a remarkably effective industrial complex and permitted our population and our resource consumption to expand-seemingly without checks. But the checks are there and we are in the midst of a sixth mass extinction event driven by our fossil-fuel consumption, our toxification of the Earth, our extensive habitat destruction, and our expanding population. This is all quite a feat given that widespread petroleum production began a bit more than 150 years ago following the discovery of abundant fuel in a field in Titusville, Pennsylvania.

The loss of biodiversity is, depending on your values, a tragic loss, a massively destabilizing loss, or a huge economic loss. Nature provides spiritual sustenance and exploring nature is restorative in many ways to many of us. We need nature. We are healthier when we have access to nature. As we learn more about food webs, and interspecific interactions more generally, we find that the loss of even a single species may be magnified, for species do not exist in isolation, they effect other species as well. For example, there are information networks all around us-even when out for a walk you can see a dog scare a bird who gives an alarm call that warns a squirrel. Without the bird, the squirrel is more vulnerable to predation. We are just beginning to appreciate the interactions between microbial diversity and organismal health. And, of course, biodiversity has enormous economic values-ranging from the tsunami protection against storms that healthy and extensive mangroves provide, to the air cleansing and $\mathrm{CO}_{2}$ sequestration that vegetation provides, to the pharmacopeia of medicines just waiting to be discovered. Bioinspired design has made swimmers swim faster and boats move more efficiently through the water.

Combatting biodiversity loss is, however, a wicked problem that is hard to solve because it is complex and requires interdisciplinary collaboration. The field of conservation biology has evolved since its founding as a crisis discipline with strong focuses on genetics and population biology in the late 1970s (Soulé and Wilcox, 1980). Practitioners now recognize the essential nature of interdisciplinary collaboration and communication. Frontiers in Conservation Science was created with this interdisciplinary collaboration in mind.

Frontiers in Conservation Science is a multidisciplinary, open-access platform dedicated to

Edited and reviewed by:

Corey J. A. Bradshaw,

Flinders University, Australia

${ }^{*}$ Correspondence: Daniel T. Blumstein marmots@ucla.edu

Received: 29 July 2020 Accepted: 27 August 2020 Published: 25 September 2020

Citation:

Blumstein DT (2020) Grand Challenges in Conservation Science.

Front. Conserv. Sci. 1:588568. doi: $10.3389 / f c 0 s c .2020 .588568$ the publication of ideas, reports, methods, and techniques that can be applied to biodiversity conservation and management. The aim of the journal is to encourage collaboration between scientists, stakeholders, and civil society to advance the conservation and management of the world's biodiversity.

Frontiers in Conservation Science recognizes that a diversity of approaches will be essential to manage our biodiversity crisis. Business-as-usual conservation and management are demonstrably not up to the challenge. Thus, the journal welcomes submissions from natural, physical, and social scientists as well as humanists whose work informs why and how we can conserve and manage biodiversity. Indeed, there is a healthy debate as to the value of instrumental values for conserving nature (e.g., Newman et al., 2017), and there is a healthy debate about the entire field of compassionate conservation (e.g., Wallach et al., 2018; Oommen et al., 2019). We welcome submissions from relatively new disciplines that are relevant to conservation-such as conservation behavior, conservation physiology, and conservation psychology to name but a few. 
The journal will initially have five core areas. Animal Conservation and a separate core area on Plant Conservation will focus on individual organisms, populations, and species, as well as their interactions (e.g., plant-pollinator interactions) as part of an ecological community. Conservation Genomics will focus on applying genetic and genomic approaches to basic and applied conservation questions. Global Biodiversity Threats will publish multi-disciplinary applied and theoretical research from the family of topics covering the drivers and patterns of biodiversity change at the global scale. Human-Wildlife Dynamics will focus on multi-disciplinary applied research from the family of topics around human-wildlife interactions. We aim to increase core areas to include more social sciences including governance, policy, and decision theory, without which effective biodiversity conservation will not be possible. Regardless of the core areas, we will encourage the submission of other highly interdisciplinary Research Topics.

While we encourage novel approaches and ideas, a shortcoming of other leading journals is that a lack of novelty is fatal and such papers are often rejected without review. We know the best evidence for interventions often are adaptations of an existing strategy to a new species, community, or location. This type of research does not tend to be seen as novel or exciting, despite it having real potential for positive conservation impact. Thus, we encourage well-designed and executed empirical studies, even if they are not novel, because we believe that these will create the necessary peer-reviewed database essential from which to draw the best applied conclusions.

A recent change-model workshop that I helped organize identified communication between academic scientists and practitioners as a major impediment in translating the newest discoveries to the field (Greggor et al., in review). Frontiers in Conservation Science will address this information gap by continuing the tradition of Frontiers journals and being Gold Open Access. Gold Open Access is only good if it does not create an impediment to publication and, between a highly competitive pricing scheme, a fee-support program for those in need, and discount pricing agreements with a growing number of institutions throughout the world, we hope that this will soon become the sought-after place to publish your best conservation science.

But effective translation means that we will also welcome submissions from academics as well as from practitioners. The change model workshop also recognized the essential value of co-creation which means that academic researchers must work more closely with managers and policy makers (whether they are natural or physical scientists, economists, or other social scientists or experts in other disciplines) in designing and implementing studies. Frontiers in Conservation Science aims to create a forum where all interested in conservation science can learn from each other and inspire each other.

Frontiers in Conservation Science will welcome papers that focus on information and actions needed to increase the size of rare populations and species, as well as those that seek to reduce or manage populations or species we deem overabundant. Human-wildlife conflicts so nicely illustrate the essential interplay between natural and social scientists because often we need to understand why a species is considered a "problem" in the first place.

But foundational insights from social sciences do not stop here. Human and natural systems are coupled (Ostrom, 2009). We need to understand viable strategies to modify human behavior in many contexts that the field of conservation psychology addresses. And we need to understand the nature and dynamics of coupled human and natural systems if we are to understand overexploitation of natural resources and humans (Brashares et al., 2014). For instance, recent work has established links between overfishing and human slavery (e.g., Tickler et al., 2018). But there are also important links between consuming wild game and childhood nutrition in developing countries (Golden et al., 2011). As the COVID-19 pandemic has so vividly illustrated, we need a foundational understanding of human behavior to manage the consumption of wild animals. We also must understand the economic value of natural systems to convince some to value them and to design and implement policies to protect them. Delaying action to address climate disruption only increases the costs and delays the benefits to humans and to biodiversity. We need to understand the complexities of decision making to enact wise and sustainable management and the field of conservation decision making works to articulate best-practice strategies to effect necessary changes.

Quality science is reproducible and Frontiers in Conservation Science will support pre-registration of protocols as well as open and accessible data and code. Pre-registration is an important step to engaging in properly reproducible science (Munafo et al., 2017), and it can help build public trust which is particularly important for studies aiming to be relevant to policy makers (Berger-Tal et al., 2019). But not all studies must be pre-registered and exploratory analyses have their place in conservation science; they should just be labeled as such (Nilsen et al., 2020). Open data and code are essential for follow-up studies and can help make analyses more accessible. Importantly, publishing data sets in an easily accessible location permits future analysis by those interested in the topic and we will encourage data publications in the journal.

A recent paper (Williams et al., 2020) noted that too many papers in conservation identified problems but failed to provide meaningful and evidence-based recommendations for positive change. It is essential to identify current and potential problems, and to identify mechanistic levers of potential change. But to be effective, conservation insights must be applied. Of course this awareness-to-action shortcoming is not restricted to conservation science; I have identified a similar problem in the field of environmental education (Saylan and Blumstein, 2011) and a lot of money is invested in basic biomedical research that is far from leading to new therapies. But, ultimately to be successful as a field, the "bench-to-bedside" aspirational aims of the US National Institute of Health and other nation's biomedical research enterprises must be adopted by the conservation science community. Thus, while foundational research is essential to report, there must be a clearly articulated way that this knowledge may ultimately be applied to solve compelling problems. I find it intellectually stimulating to design and implement applied 
research that explicitly addresses current conservation failures. Thus, all papers in Frontiers in Conservation Science must articulate, in a separate section, their conservation and/or policy relevance. We will also seek papers illustrating both applied conservation success and failures, because we can learn equally from both.

This is an exciting time to create a new journal in conservation science. We aim to publish thought-leading reviews, systematic reviews and meta-analyses, horizon scans as well as quality empirical papers from relevant disciplines. We hope that the accessibility of this literature will help bridge

\section{REFERENCES}

Berger-Tal, O., Greggor, A. L., Macura, B., Adams, C. A., Blumenthal, A., Bouskila, A., et al. (2019). Systematic reviews and maps as tools for applying behavioral ecology to management and policy. Behav. Ecol. 30, 1-8. doi: 10.1093/beheco/ary130

Brashares, J. S., Abrahms, B., Fiorella, K. J., Golden, C. D., Hojowski, C. E., Marsh, R. A., et al. (2014). Wildlife decline and social conflict. Science 345, 376-378. doi: $10.1126 /$ science. 1256734

Golden, C. D., Fernald, L. C. H., Brashares, J. S., Rasolofoiaina, B. J. R., and Kremen, C. (2011). Benefits of wildlife consumption to child nutrition in a biodiversity hotspot. Proc. Natl. Acad. Sci. U.S.A. 108, 19653-19656. doi: 10.1073/pnas.1112586108

Munafo, M. R., Nosek, B. A., Bishop, D. V. M., Button, K. S., Chambers, C. D., Percie du Sert, N., et al. (2017). A manifesto for reproducible science. Nat. Hum. Behav. 1:0021. doi: 10.1038/s41562-016-0021

Newman, J. A., Warner, G., and Linquist, S. (2017). Defending Biodiversity: Environmental Science and Ethics. Cambridge: Cambridge University Press. doi: $10.1017 / 9781139024105$

Nilsen, E. B., Bowler, D. E., and Linnell, J. D. C. (2020). Exploratory and confirmatory research in the open science era. J. Appl. Ecol. 57, 842-847. doi: 10.1111/1365-2664.13571

Oommen, M. A., Cooney, R., Ramesh, M., Archer, M., Brockington, D., Buscher, B., et al. (2019). The fatal flaws of compassionate conservation. Conserv. Biol. 33, 784-787. doi: 10.1111/cobi.13329

Ostrom, E. (2009). A general framework for analyzing sustainability of socialecological systems. Science 325, 419-422. doi: 10.1126/science.1172133 the academic-practitioner information gap so that conservation outcomes will be improved. There clearly is a compelling need to improve on what we have been doing to address our biodiversity crisis and we hope that Frontiers in Conservation Science will help catalyze the interdisciplinary communication required to do so.

\section{AUTHOR CONTRIBUTIONS}

The author confirms being the sole contributor of this work and has approved it for publication.

Saylan, C. S., and Blumstein, D. T. (2011). The Failure of Environmental Education (and How We Can Fix It). Berkeley CA: University of California Press. doi: $10.1525 / 9780520948723$

Soulé, M., and Wilcox, B. A. (eds.). (1980). Conservation Biology: An EvolutionaryEcological Perspective. Sunderland, MA: Sinauer Associates.

Tickler, D., Meeuwig, J. J., Bryant, K., David, F., Forrest, J. A. H., Gordon, E., et al. (2018). Modern slavery and the race to fish. Nat. Commun. 9:4643. doi: 10.1038/s41467-018-07118-9

Wallach, A. D., Bekoff, M., Batavia, C., Nelson, M. P., and Ramp, D. (2018). Summoning compassion to address the challenges of conservation. Conserv. Biol. 32, 1255-1265. doi: 10.1111/cobi. 13126

Williams, D. R., Balmford, A., and Wilcove, D. S. (2020). The past and future role of conservation science in saving biodiversity. Conserv. Lett. 2020:e12720. doi: $10.1111 /$ conl.12720

Conflict of Interest: The author declares that the research was conducted in the absence of any commercial or financial relationships that could be construed as a potential conflict of interest.

Copyright (c) 2020 Blumstein. This is an open-access article distributed under the terms of the Creative Commons Attribution License (CC BY). The use, distribution or reproduction in other forums is permitted, provided the original author(s) and the copyright owner(s) are credited and that the original publication in this journal is cited, in accordance with accepted academic practice. No use, distribution or reproduction is permitted which does not comply with these terms. 